\title{
Clinical and electrophysiological characteristics of a transvenous atrial lead
}

\author{
IB KRUSE, LARS RYDEN, AND BO YDSE \\ From the Departments of Anesthesiology and Medicine, Central Hospital, S-541 01 Skövde, Sweden
}

SUMMARY Despite some reports on the use of the atrial transvenous endocardial lead, Medtronic 6991, there is still very little information on the electrophysiological properties of the lead. A lead extension wire was connected to the atrial lead, passed subcutaneously, and brought through the abdominal skin. $\mathrm{P}$ wave amplitude, threshold of stimulation, and electrode resistance were repeatedly determined through the atrial lead during four weeks after the electrode insertion in 17 patients. Mean $P$ wave amplitude at insertion was $3.7 \pm 1.0$ (mean \pm SD) $\mathrm{mV}$. It decreased significantly to a lowest mean level of $2.3 \pm 0.9 \mathrm{mV}$ after one week. From that time there were only small variations. In the supine position and with normal breathing there was a spontaneous variation in the $P$ wave amplitude of \pm 15 per cent. $P$ wave amplitude was only to a minor extent influenced by body position and maximum breathing movements. The threshold of stimulation was $1.7 \pm 0.7 \mathrm{~V}$ (impulse duration $0.5 \mathrm{~m} 3$ ) at the time of electrode insertion. It increased to $2 \cdot 7 \pm 1 \cdot 0 \mathrm{~V}$ after four weeks. The electrode resistance varied about 600 ohms.

A total of 28 patients received an atrial transvenous endocardial lead. Three electrode dislocations occurred, all during the first 24 hours; apart from these three, the electrodes were connected easily to the intended pacemakers and have functioned well during the observation period of between two and 24 months. In conclusion, the transvenous endocardial atrial lead Medtronic 6991 has shown attractive qualities. The electrophysiological data recorded are suitable for the pacemakers in use. So far this atrial lead seems promising and deserves further evaluation.

Despite the increasing number of patients with pacemakers, there has not been a corresponding increase in the use of atrial synchronous and atrial inhibited pacing. In Sweden not more than 1 per cent of initially implanted pacemakers are atrial synchronous (Karlöf and Lagergren, 1973; Edhag, 1977). Many patients would, however, improve haemodynamically with an atrial inhibited or atrial synchronous pacemaker (Lagergren et al., 1966; DeSanctis, 1971; Furman, 1973). The reason for the limited use of atrial pacing is probably the lack of an electrode which combines a simple technique of introduction with long-term reliability. Recently promising results have been reported by the use of a transvenous J-shaped atrial tined lead (Smyth et al., 1976; Kleinert et al., 1977). These reports deal with the technique of introduction and electrophysiological characteristics of the lead at the time of electrode insertion.

The present investigation was undertaken to study the electrophysiological characteristics of the Received for publication 17 April 1979 atrial electrode by means of repeated measurements throughout a period of four weeks after the introduction of the electrode. The report also contains information about our present clinical experience with the electrode.

\section{Subjects and methods}

PATIENTS

The subjects consisted of 28 patients; pertinent data from these are presented in Table 1.

THE LEAD

The lead (Medtronic model 6991) has a unipolar electrode and is designed for transvenous introduction. It is made of a silicone rubber-insulated nickel alloy lead which ends in a $10 \mathrm{~mm}^{2}$ platinum electrode tip. The distal part of the electrode is preformed like a $\mathrm{J}$ the radius of which is $1.3 \mathrm{~cm}$. The short leg of this $\mathrm{J}$ is furnished with nine tines of silicon rubber. The J-shape and the tines facilitate fixation of the electrode tip within the right atrial 
appendage. The first five leads were used unmodified. Subsequently the tines were trimmed. In the beginning this trimming gave the tines the shape of a 'Christmas-tree'. The trimming of the lead has become increasingly more pronounced. Thus, in the last five patients only $5 \mathrm{~mm}$ have been left of the three tines closest to the electrode tip while the others have been cut away entirely (Fig. 1).

The electrode has usually been introduced via the external jugular vein (19 patients). The internal jugular vein (five patients) or the cephalic vein (four patients) have been used when the external jugular vein was too small. During the introduction the distal portion of the lead has been straightened by means of a stylet. This is withdrawn as soon as the lead has reached the right atrium. When the distal part of the electrode has recovered the Jshape, the lead is rotated in order to position the tip in an anterior and medial direction. Thereafter the lead is slightly withdrawn. During this procedure the electrode tip usually recoils by itself into the right atrial appendage.

The electrode position has been accepted when the tip of the electrode points medially and anteriorly, swings sideways with each atrial contraction, and only makes minor movements within the right atrial appendage while the patient takes a deep breath or is coughing. The J-shape should be maintained during maximal breathing movements. Finally it should be possible to record a stable atrial electrogram through the lead. A typical electrode position is shown in Fig. 2. After obtaining a stable electrode position the lead has been fixed at the site of entry into the vein by means of an anchoring sleeve.

\section{ELECTROPHYSIOLOGICAL MEASUREMENTS}

At the time of introduction the atrial lead was connected to a lead extension wire in 17 of the patients. This was passed subcutaneously and externalised through the abdominal skin. Patients in whom a pacemaker was implanted previously retained this wire during the investigation period. In these cases the extension lead was removed at the time of pacemaker replacement. In other patients the final pacemaker was implanted directly. In these, a specially constructed extension lead made it possible to extract it by means of direct traction.

$P$ wave amplitude, threshold of stimulation, and total electrode resistance were measured repeatedly during the first week and subsequently once a week during one month after lead insertion. The measurements were performed with the patients in the supine position and with normal breathing. A basic $P$ wave amplitude was determined as the mean value of five consecutive $P$ waves. Furthermore, changes in $P$ wave amplitude during maximum inspiratory and expiratory apnoea and in different body positions (standing, sitting, lying on left and right side) were determined as the maximal percentage change from the basic $P$ wave amplitude. The $P$ waves were measured by means of a Mingograph 82 (SiemensElema, Sweden), with a frequency response 0 to $1250 \mathrm{~Hz}$. All $\mathrm{P}$ wave recordings were bipolar with the reference point (needle electrode) below the clavicle at the site of pacemaker implantation. The stimulation threshold of the atrium was determined by means of the Medtronic 5300 Pacemaker System Analyzer. The threshold was determined at a stimulation impulse duration of $0.2 ; 0.4 ; 0.5$;
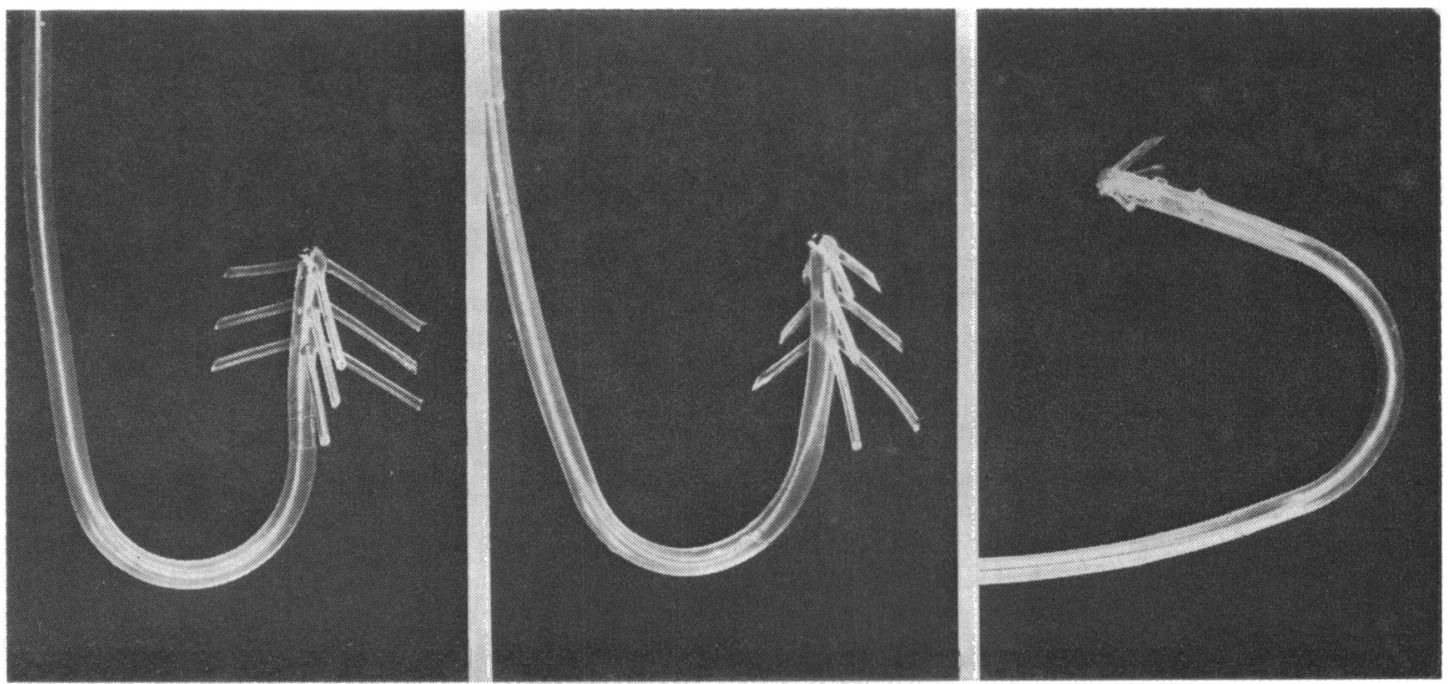

Fig. 1 Differently trimmed electrode tips. The picture on the right shows the present degree of trimming. 
1.0 ; and $1.5 \mathrm{~ms}$. The threshold was defined as the minimal impulse amplitude constantly stimulating the atria. The threshold was determined in volts and resulting current. The electrode lead resistance was determined at a stimulation impulse duration of $0.5 \mathrm{~ms}$ and at an impulse amplitude of $5.0 \mathrm{~V}$.

Statistical analysis was performed using Student's $t$ test for paired differences, and a $P$ value of $<0.05$ was accepted as statistically significant.

\section{Results}

\section{P WAVE AMPLITUDE}

The variation of the $P$ wave amplitude versus time is presented in Fig. 3. The mean $P$ wave amplitude \pm SD for the group at the time of insertion was $3.7 \pm 1.0 \mathrm{mV}$. Thereafter it decreased significantly $(P<0.01)$ to a lowest mean level $2.3 \pm 0.9 \mathrm{mV}$ after one week. From that time there were only small
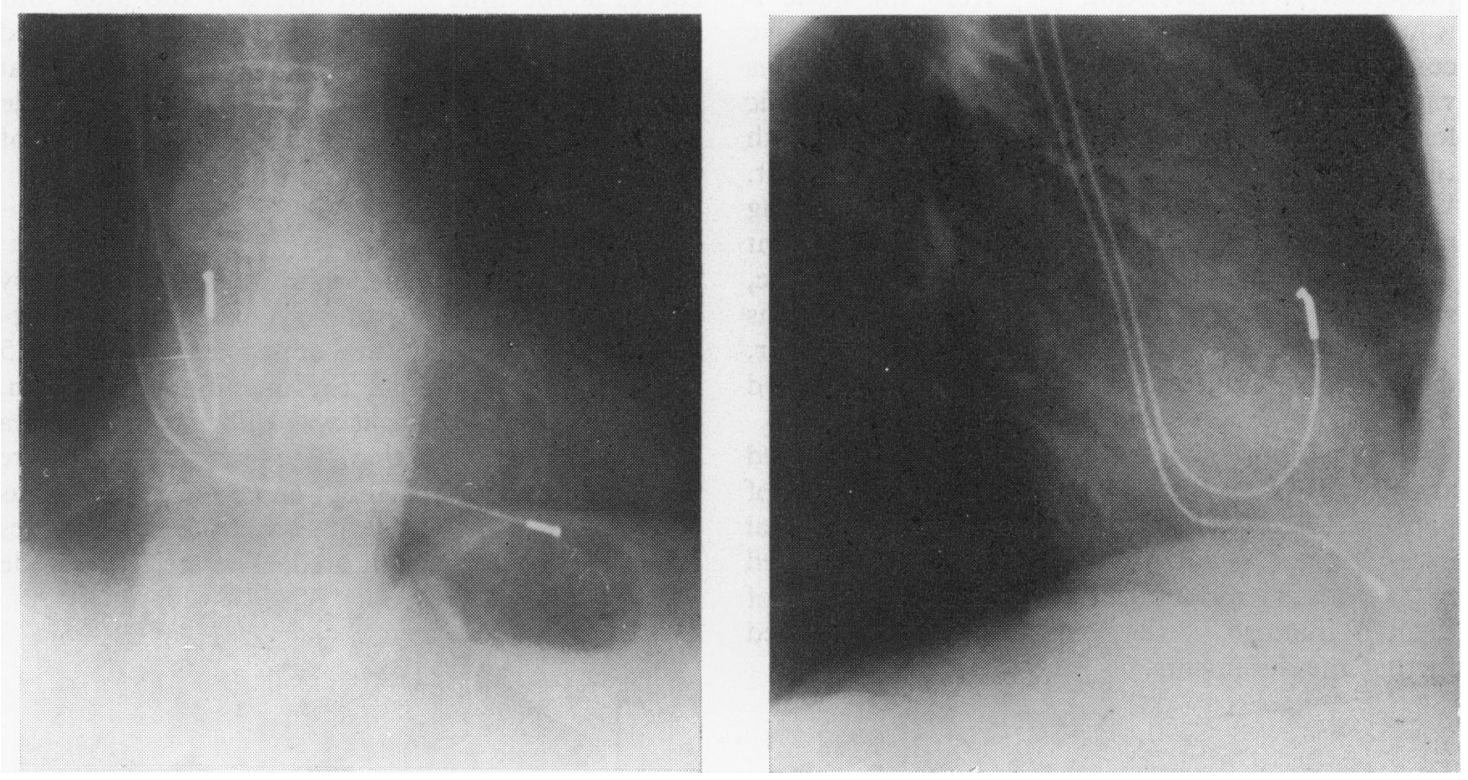

Fig. 2 A typical position of the $\mathcal{f}$ electrode in the right atrial appendage. The right and left panels show respectively lateral and frontal planes.

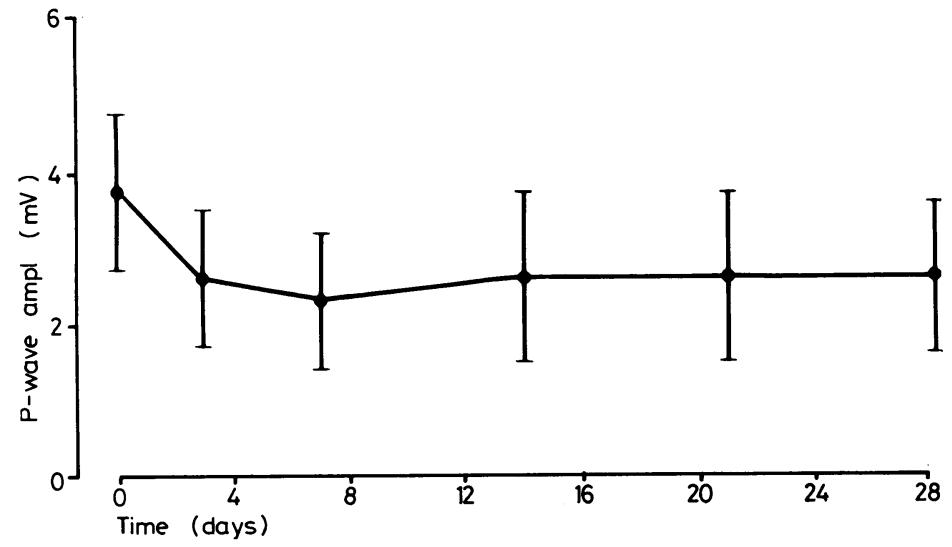

Fig. $3 P$ wave amplitude in $m V$ from the time of lead introduction and during four weeks. Mean value $\pm S D$. 
changes during the remaining part of the observation period. These changes were not statistically significant. In Fig. 4 individual $P$ wave amplitudes are presented at the time of electrode insertion and after one and four weeks. All patients except one have an initial $P$ wave amplitude of at least $2.0 \mathrm{mV}$. In every case the $\mathbf{P}$ wave decreased from the moment of insertion to a stable level after one week. The mean reduction is about 40 per cent.

Fig. 5 presents individual spontaneous $P$ wave variations during normal breathing with the patient in the supine position. The variation presented is the deviation $( \pm)$ from the basic $P$ wave level mentioned above (that is the mean of five consecutive $\mathbf{P}$ waves). In general the spontaneous variation is about \pm 15 per cent from this basic level. Though the variability decreases a little with time this difference is not statistically significant. When the $\mathbf{P}$ wave amplitude was recorded during maximal inspiration and expiration, with the patient in the supine position, lying on the right or left side; sitting, or standing, there were some variations in the $\mathbf{P}$ wave amplitude. These activities, however, did not induce deviations exceeding those reported during normal breathing in the supine position.

In Fig. 4 to 5 the numbers of patients observed are not in accordance with the total numbers of patients listed in Table 1. The electrophysiological investigations during four weeks were performed in 17 patients receiving a $\mathrm{J}$ electrode. In some of them a fracture of the extension wire prevented further measurements.

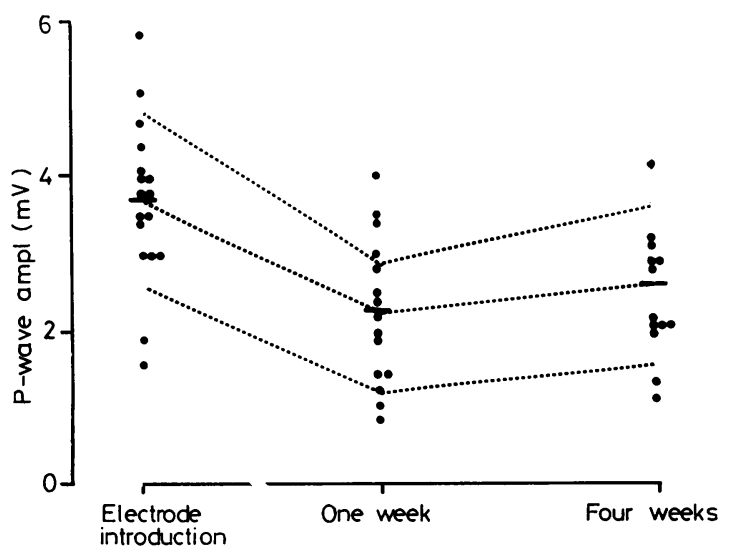

Fig. $4 \quad P$ wave amplitude in $m V$ at the time of lead insertion and one and four weeks thereafter. Individual values are presented together with the mean $\pm S D$ for the total group of patient.

\section{ATRIAL STIMULATION THRESHOLD}

The stimulation threshold of the right atrium could only be determined in seven patients in whom continuous ventricular pacing did not make it impossible to detect stimulated $P$ waves and/or stimulation of the right atrium did not inhibit the pacemaker in use.

The threshold of stimulation at an impulse duration of $0.5 \mathrm{~ms}$ was initially $1.7 \pm 0.7 \mathrm{~V}$ (mean \pm $\mathrm{SD}$ ), increased to $2.5 \pm 0.9 \mathrm{~V}$ after one week, and 2.7 \pm 1.0 after four weeks (Fig. 6). This increase did not reach statistical significance. The strength duration curves at the time of lead insertion and after four weeks are presented in Fig. 7. The curve obtained after one week was practically similar to the one at four weeks. The total resistance of the electrode system was about $600 \mathrm{ohms}$ throughout the time of observation (Table 2).

\section{CLINICAL EXPERIENCE}

The insertion of the electrode was usually an easy procedure. The mean time of positioning the electrode within the right atrial appendage was 10 to 15 minutes measured from the opening of the vein. In two of the patients it was difficult to obtain a suitable electrode position. The operative procedure was then prolonged to about one hour. So far it has been possible to position an atrial lead in all cases where this has been indicated. The atrial electrode

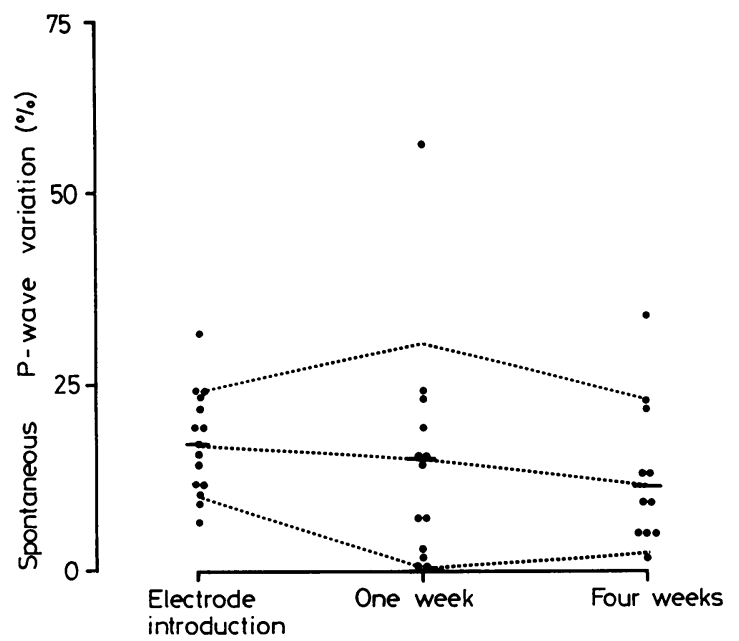

Fig. 5 Spontaneous $P$ wave variation at the time of lead insertion and one and four weeks thereafter. Individual values are presented, together with the mean $\pm S D$ for the total group of patients. The deviation $( \pm)$ from the mean $P$ wave amplitude is given in per cent along the vertical axis. 
has functioned well in all cases. One patient (case 1) received a VVI pacemaker when he later developed repeated attacks of atrial fibrillation. These were not related to the introduction of the atrial lead.

The electrode was dislodged in three cases (cases 4, 5, and 8). All dislodgements occurred within 24 hours after the positioning. In one patient a poor fixation of the electrode at the site of introduction into the internal jugular vein probably contributed (case 5). In case 4 there was a large difference between the position of the heart in the standing and supine position. In this patient the electrode dislodged when the patient got up for the first time after the operation. Probably the lead became too stretched within the atrium in the upright position. The explanation of the electrode dislodgement in case 8 was probably that a previously placed ventricular lead had developed a loop within the right atrium because the heart size had diminished. This loop 'whipped' the J lead with every heart beat resulting in dislodgement. Before repositioning of the atrial lead the ventricular lead was retracted in order to eliminate the loop. All the electrodes that were dislodged were easily repositioned and have thereafter functioned properly. The observation time at the end of December 1978 is presented in Table 1.

Apart from leads becoming dislodged there have been no complications related to the use of the

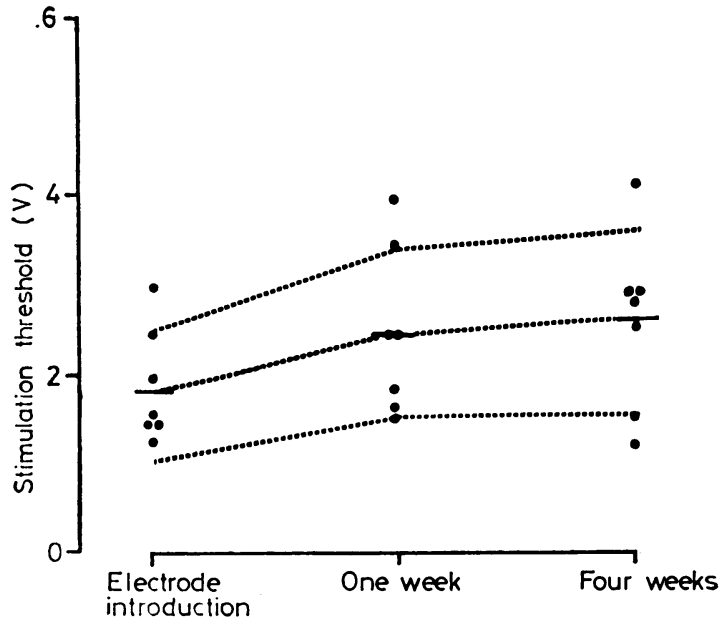

Fig. 6 Right atrial stimulation threshold in volts (V) at an impulse duration of $0.5 \mathrm{~ms}$ at the time of lead insertion and one and four weeks therafter. Individual values are presented together with the mean $\pm S D$ for the total group of patients. atrial electrode. In one patient (case 12), atrial synchronous pacing was started as one of several attempts to relieve advanced left ventricular failure. This patient died about one month after lead insertion. At necropsy there were no signs of irritation or thrombus formation around the tip of the electrode. Only the tines closest to the tip of the electrode were positioned within the right atrial appendage, while the other tines were outside.

\section{Discussion}

Different methods have been used for the introduction of atrial electrodes. The electrode can be sutured to the atrial wall via a thoracotomy (Center et al., 1963; Center and Nathan, 1966). Another approach is the mediastinal by means of mediastinoscopy as outlined by Carlens et al. (1965). Though this method has proved reliable with $\mathbf{P}$ wave sensing (Carlens et al., 1977), it is not suitable for atrial pacing. A thoracotomy implies major surgery and though mediastinoscopy is not a particularly large operative procedure it requires general anaesthesia. Such factors have obviously limited the widespread use of these methods for atrial pacing and sensing. The transvenous route does overcome such restrictions. Early experiences with transvenous atrial electrodes were discouraging because of a high proportion of electrode dislodgement and increase in pacing threshold (Rodewald et al., 1964; Center et al., 1967; DeSanctis, 1971). One way of overcoming these problems is the use of

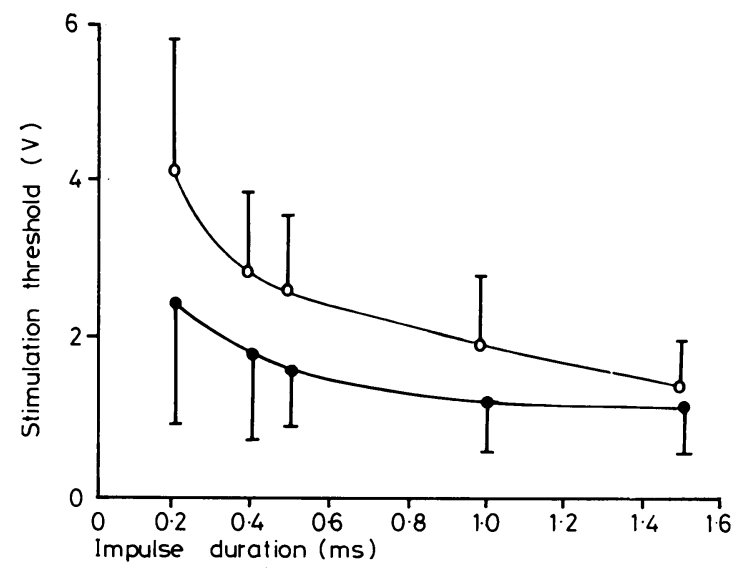

Fig. 7 Strength duration curves in the right atrium. Stimulation threshold in volts $(V) \pm S D$ along the vertical axis and impulse duration in milliseconds along the horizontal. , at time of lead insertion; $\bigcirc$, four weeks after lead insertion. 
Table 1 Selected data from patients (as per December 1978)

\begin{tabular}{|c|c|c|c|c|c|c|c|}
\hline $\begin{array}{l}\text { Case } \\
\text { no. }\end{array}$ & $\begin{array}{l}\text { Age } \\
(y)\end{array}$ & Sex & Diagnosis & Arrhythmia & $\begin{array}{l}\text { OBS time } \\
\text { (mth) }\end{array}$ & $\begin{array}{l}\text { Type of } \\
\text { pacemaker }\end{array}$ & Remarks \\
\hline $\begin{array}{l}1 \\
2 \\
3\end{array}$ & $\begin{array}{l}86 \\
62 \\
65\end{array}$ & $\begin{array}{l}\mathrm{M} \\
\mathrm{M} \\
\mathrm{M}\end{array}$ & $\begin{array}{l}\text { Coronary heart disease, myocardial infarct } \\
\text { AV conduction disturbance } \\
\text { Coronary heart disease, myocardial infarction }\end{array}$ & $\begin{array}{l}\text { AV II } \text { II }^{\circ} \mathrm{III}^{\circ} \\
\text { AV III } \\
\text { Excessive } \\
\text { bradycardia } \\
\text { upon carotid } \\
\text { stimulation }\end{array}$ & $\begin{array}{l}24 \\
22 \\
22\end{array}$ & $\begin{array}{l}\text { VVI } \\
\text { VDT/I } \\
\text { VAT }\end{array}$ & Developed atrial fibrillation \\
\hline $\begin{array}{l}4 \\
5 \\
6 \\
7\end{array}$ & $\begin{array}{l}64 \\
67 \\
65 \\
59\end{array}$ & $\begin{array}{l}\text { F } \\
\mathbf{M} \\
\mathbf{F} \\
\mathbf{F}\end{array}$ & $\begin{array}{l}\text { AV conduction disturbance } \\
\text { AV conduction disturbance } \\
\text { AV conduction disturbance } \\
\text { AV conduction disturbance }\end{array}$ & $\begin{array}{l}\text { AV III } \\
\text { AV III } \\
\text { AV } I^{\circ}-I^{\circ} \\
\text { AV III }\end{array}$ & $\begin{array}{l}20 \\
19 \\
19 \\
19\end{array}$ & $\begin{array}{l}\text { VDT } / I \\
\text { VDT/I } \\
\text { VDT/I } \\
\text { VDT/I }\end{array}$ & $\begin{array}{l}\text { Dislocation } \\
\text { Dislocation }\end{array}$ \\
\hline $\begin{array}{r}8 \\
9 \\
10 \\
11\end{array}$ & $\begin{array}{l}82 \\
59 \\
63 \\
60\end{array}$ & $\begin{array}{l}\mathbf{F} \\
\mathbf{M} \\
\mathbf{F} \\
\mathbf{F}\end{array}$ & $\begin{array}{l}\text { Sick sinus syndrome } \\
\text { Cardiomyopathy } \\
\text { Sick sinus syndrome } \\
\text { AV conduction disturbance }\end{array}$ & $\begin{array}{l}\text { SA } \\
\text { AV III } \\
\text { SA } \\
\text { AV III }\end{array}$ & $\begin{array}{l}17 \\
16 \\
16 \\
14\end{array}$ & $\begin{array}{l}\text { AAI } \\
\text { VDT/I } \\
\text { AAI } \\
\text { VDT/I }\end{array}$ & Dislocation \\
\hline 12 & 76 & $\mathbf{M}$ & Coronary heart disease, myocardial infarction & AV III $^{\circ}$ & 1 & VDT/I & Dead \\
\hline 13 & 67 & $\mathbf{F}$ & AV conduction disturbance & AV III ${ }^{\circ}$ & 10 & VDT/I & \\
\hline 14 & 69 & $\mathbf{M}$ & AV conduction disturbance & AV III $^{\circ}$ & 10 & VAT & \\
\hline 15 & 44 & $\mathbf{M}$ & AV conduction disturbance & AV III $^{\circ}$ & 10 & VDT/I & \\
\hline 16 & 69 & $\mathbf{F}$ & Perimyocarditis & AV III ${ }^{\circ}$ & 10 & VDT/I & \\
\hline 17 & 55 & $\mathbf{F}$ & AV conduction disturbance & AV $I^{\circ}-I^{\circ} I^{\circ}$ & 9 & VDT/I & \\
\hline 18 & 65 & $\mathbf{M}$ & Hypertension, AV conduction disturbance & AV III ${ }^{\circ}$ & 9 & VDT/I & \\
\hline 19 & 77 & $\mathbf{M}$ & AV conduction disturbance & AV III ${ }^{\circ}$ & 8 & $\mathrm{VDT} / \mathbf{I}$ & \\
\hline 20 & 63 & $\mathbf{M}$ & AV conduction disturbance & AV III ${ }^{\circ}$ & 8 & VDT/I & \\
\hline 21 & 49 & $\mathbf{F}$ & AV conduction disturbance VPC & AV II $^{\circ}-\mathrm{III}^{\circ}$ & 7 & VAT & \\
\hline 22 & 67 & $\mathbf{M}$ & Sick sinus syndrome & SA & 7 & AAI & \\
\hline 23 & 79 & $\mathbf{F}$ & Sick sinus syndrome & SA & 6 & AAI & \\
\hline 24 & 70 & $\mathbf{M}$ & AV conduction disturbance & AV III $^{\circ}$ & 6 & $\mathrm{DDT} / \mathrm{I}$ & Replaced by VAT \\
\hline 25 & 64 & $\mathbf{M}$ & AV conduction disturbance & AV III ${ }^{\circ}$ & 5 & VDT/I & \\
\hline 26 & 58 & $\mathbf{F}$ & AV conduction disturbance & AV III ${ }^{\circ}$ & 4 & $\mathbf{V D T} / \mathbf{I}$ & \\
\hline 27 & 58 & $\mathbf{M}$ & AV conduction disturbance & AV III ${ }^{\circ}$ & 3 & VDT/I & \\
\hline 28 & 57 & $\mathbf{F}$ & AV conduction disturbance & AV III $^{\circ}$ & 2 & VAT & \\
\hline
\end{tabular}

*According to Parsonnet et al. (1974).

AV $I^{\circ}-\mathrm{III}^{\circ}$, atrioventricular block of the first-third degree; SA, sinus arrest; VPC, ventricular premature capture.

Table 2 Electrode resistance $(\Omega)$ at various times after electrode insertion

\begin{tabular}{llll}
\hline & At insertion & 1 week & 4 weeks \\
\hline Mean & 575 & 590 & 728 \\
SD & 221 & 210 & 267 \\
no. & 7 & 6 & 7 \\
\hline
\end{tabular}

coronary sinus leads (Moss, 1975; Moss and Rivers, 1977). Another approach has been the design of preformed so-called J leads (Kastor et al., 1969; Smyth et al., 1969, 1971; Geddes et al., 1978). The introduction of small hooks at the electrode tip is another method of increasing the stability of the electrode position within the right atrium originally suggested by Rosenkranz and Schaldach (1971) and further improved by Funke and Schaldach (1977).

The lead used in the present investigation was designed by Smyth et al. (1976). It presents a preformed J shape with three rows of tines close to the electrode tip. Both these qualities are intended to facilitate the anchoring of the lead within the right atrial appendage where the tines may entangle with the trabeculae. Promising clinical results with this lead have also been presented by Kleinert et al. (1977) and Citron et al. (1978).

The clinical experiences obtained in the present series of patients are in good agreement with the findings in previous reports. The lead is usually easy to position within the right atrial appendage and the subsequent function has been satisfactory during a mean observation period of 11 months (range two to 24). Of the three lead dislodgements, probably at least two (cases 4 and 5) were related to the early operative technique. A 10 per cent dislodgement rate in total may seem discouraging. It should, however, be remembered that repositioning was a simple procedure resulting in stable function and that there has been no displacement in the last 20 patients. In the previous reports on the lead the dislodgement rate varies between 0 and 6 per cent (Smyth et al., 1976; Kleinert et al., 1977; Citron et al., 1978). In the patient who died (case 12) it was obvious that only the tines closest to the electrode tip were entangled in the trabeculae of the right atrial appendage while the other tines re- 
mained outside. Further studies on the anatomy of a substantial number of human right atria (at necropsy) were performed. In conclusion it was considered unlikely that all tines could enter the right atrial appendage. This led to an increasingly more pronounced trimming of the tines (Fig. 1), a procedure which simplified the introduction of the lead into the vein as the untrimmed lead is relatively large. The lead function was not obviously impaired by the trimming.

Apart from the data obtained at insertion of the lead, the electrophysiological characteristics of the lead have not so far been reported. The acute $P$ wave amplitudes obtained in the present study are by and large comparable with those obtained by other investigators using the same (Smyth et al., 1976; Kleinert et al., 1977) or different transvenous atrial leads (Rosenkranz and Schaldach, 1971; Cappelen and Hall, 1974; Furman et al., 1977; Geddes et al., 1978). The relatively minor differences may be explained by the technique of measuring especially as regards frequency response of the recording equipment (Citron et al., 1978). The decrease in $P$ wave amplitude which has been observed in the present material is of practical importance. Acceptance of a too low $\mathrm{P}$ wave may impose a risk of later loss of sensing. The input sensitivity of the atrial amplifier in the atrial synchronous and inhibited pacemakers available is usually about or somewhat below 1.0 $\mathrm{mV}$. One of our patients had a $\mathrm{P}$ wave just less then $1.0 \mathrm{mV}$ after one and four weeks and needed a pacemaker with a particular high $P$ wave sensitivity. Taking the spontaneous $P$ wave variability into consideration the importance of this decrease in $P$ wave amplitude is still more underlined. On the assumption of an average 50 per cent decrease of the $P$ wave amplitude from the level at insertion of the lead (average reduction $40 \%$ + spontaneous variability), the $P$ wave should be well above $2 \mathrm{mV}$ to be acceptable. In doubtful cases it is advisable to wait one week before final pacemaker implantation. At one week the $P$ wave seems to reach the lowest level and a final decision can be taken about the choice of $P$ wave sensitivity of the pacemaker. The present results also indicate that recording maximal and minimal $\mathbf{P}$ waves with the patient breathing normally and in the supine position should be sufficient when studying $P$ wave variability. This can obviously be performed at the time of lead insertion since further changes are small. The cause of the decreasing $\mathbf{P}$ wave amplitude might be tissue reaction at the site of contact between the electrode tip and myocardium.

The threshold of stimulation of the right atrium was higher than that usually obtained in the right ventricle. The strength duration curves at the time of lead insertion are comparable to those reported previously (Smyth et al., 1976; Kleinert et al., 1977). The observed increase in pacing threshold was most pronounced during the first week after lead insertion and thereafter only a slight increase occurred. The increase was not statistically significant. This was probably related to the limited number of patients observed, and in absolute values the increase was not unimportant. The implication of this is that when necessary it will be possible to make a fairly accurate estimate of the final pacing threshold only one week after insertion of the lead. It should be emphasised that the J lead itself may never be exteriorised because of the risk of infection. A determination of the stimulation threshold and/or $P$ wave amplitude should always be performed by means of a lead extension wire which, after subcutaneous passage, is externalised far away from the vein used for electrode insertion. An alternative way is to use pacemakers with a high $P$ wave sensitivity or high output voltage in patients with low $P$ waves or high thresholds of stimulation. However, we think these pacemakers should whenever possible be avoided because of an increased risk of electrical interference and a higher battery drainage.

Whether the $\mathbf{P}$ wave amplitudes and atrial stimulation thresholds observed at four weeks are stable or not remains to be investigated. It seems probable that further changes should at least be small as compared with those already established by that time because the greater part of the change appears to have occurred after one week. Furthermore, experience gained from ventricular pacing electrodes favours this belief (Siddons and Sowton, 1967).

The electrophysiological characteristics of the J shaped, tined atrial transvenous lead used in general are suitable for the available atrial synchronous and inhibited pacemakers. Clinical experience so far has been encouraging. However, there should be a larger number of patients and a longer followup, including long-term electrophysiology, before more definite conclusions can be made concerning the electrode. Thus this lead is qualified beyond any doubt for further use and may be the key to a justified increase in atrial synchronous and atrial inhibited pacing.

We thank Dr Richard Sutton for reviewing the manuscript.

\section{References}

Cappelen, C., and Hall, K. V. (1974). Pervenous atrial electrode. Scandinavian Fournal of Thoracic and Cardiovascular Surgery, 8, 115-118. 
Carlens, E., Ericsson, M., Levander-Lindgren, M., and Pehrsson, K. (1977). Detector electrode introduced by mediastinoscopy for atrial triggered cardiac pacing. A follow-up study of electrode function in 82 patients. British Heart Fournal, 39, 1265-1272.

Carlens, E., Johansson, L., Karlöf, I., and Lagergren, $H$. (1965). New method for atrial-triggered pacemaker treatment without thoracotomy. Fournal of Thoracic and Cardiovascular Surgery, 50, 229-232.

Center, S., Castillo, C. A., and Keller, W. (1967). Permanent pervenous synchronous pacing of the heart. Annals of Thoracic Surgery, 4, 218-231.

Center, S., and Nathan, D. A. (1966). The synchronous pacer: three years of clinical experience with 45 cases. American Surgeon, 164, 862-866.

Center, S., Nathan, D., Wu, C-Y., Samet, P., and Keller, W. (1963). The implantable synchronous pacer in the treatment of complete heart block. fournal of Thoracic and Cardiovascular Surgery, 46, 744-753.

Citron, P., Smyth, N. P. D., Kleintrt, M., and Kahn, A. (1978). Clinical experience with a new transvenous atrial lead. Chest 73, 193-197.

DeSanctis, R. W. (1971). Diagnostic and therapeutic uses of atrial pacing. Circulation, 43, 748-761.

Edhag, O. (1977). Survey on long term cardiac pacing in Denmark, Finland, Norway and Sweden in 1973-75. In Cardiac Pacing. Proceedings of the Vth International Symposium Tokyo, March 14-18, 1976, pp. 561-63, ed Y. Watanabe. Excerpta Medica, Amsterdam and Oxford.

Funke, H. D., and Schaldach, M. (1977). Eine einfach und zuverlässig im Vorhof anzubringende Herschrittmacher-Elektrode. Deutsche medizinische Wochenschrift, 102, 819-822.

Furman, S. (1973). Therapeutic uses of atrial pacing. American Heart fournal, 86, 835-840.

Furman, S., Hurzeler, P., and DeCaprio, V. (1977). Cardiac pacing and pacemakers, III. Sensing the cardiac electrogram. American Heart fournal, 93, 794-801.

Geddes, J. S., Webb, S. W., and Clements, I. P. (1978). Clinical experience with transvenous atrial pacing. British Heart fournal, 40, 589-595.

Karlöf, I., and Lagergren, H. (1973). Survey of pacemaker treatment in Denmark, Finland, Norway and Sweden in 1972. In Cardiac Pacing, pp. 82-87, ed H. J. Th. Thalen. Van Gorcum, Assen.

Kastor, J. A., DeSanctis, R. W., Leinbach, R. C. Harthorne, J. W., and Wolfson, I. N. (1969). Long- term pervenous atrial pacing. Circulation, 40, 535-544.

Kleinert, M., Bock, M., and Wilhemi, F. (1977). Clinical use of a new transvenous atrial lead. American fournal of Cardiology, 40, 237-242.

Lagergren, H., Johansson, L., Karlöf, I., and Thornander, H. (1966). Atrial-triggered pacemaking without thoracotomy. Apparatus and results in 20 cases. Acta Chirurgica Scandinavica, 132, 678-699.

Moss, A. J. (1975). Therapeutic uses of permanent pervenous atrial pacemakers. Fournal of Electrocardio$\log y, 8,373-380$.

Moss, A. J., and Rivers, R. J., jun (1977). Atrial pacing using the coronary vein approach: ten year experience with 50 patients (abstract). Circulation, 55 and 56, Suppl. III, 13.

Parsonnet, V., Furman, S., and Smyth, N. P. D. (1974). Implantable cardiac pacemakers status report and resource guideline. Pacemaker study group. Circulation, 50, A-21-A-35.

Rodewald, G., Giebel, O., Harms, H., and Scheppokrat, K. D. (1964). Intravenös-intrakardiale Applikation von vorhofsgesteuerten elektrischen Schrittmachern. Zeitschrift für Kreislaufforschung, 53, 860-864.

Rosenkranz, K. A., and Schaldach, M. (1971). Transvenös-endokardiale Vorhofsteuerung von Schrittmachern. Deutsche medizinische Wochenschrift, 96, 680-686.

Siddons, H., and Sowton, E. (1967). Cardiac Pacemakers, pp. 167-173. Charles C. Thomas, Springfield, Illinois.

Smyth, N. P. D., Citron, P., Keshishian, J. M., Garcia, J. M., and Kelly, L. C. (1976). Permanent pervenous atrial sensing and pacing with a new J-shaped lead. Fournal of Thoracic and Cardiovascular Surgery, 72, 565-570.

Smyth, N. P. D., Keshishian, J. M., Basu, A. P., Bacos, J. M., Massumi, R. A., Fletcher, R. D., and Baker, N. R. (1971). Permanent transvenous pacing. An experimental and clinical study. Annals of Thoracic Surgery, 11, 360-370.

Smyth, N. P. D., Vasarhelyi, L., McNamara, W., and Kakascik, G. E. (1969). A permanent transvenous atrial electrode catheter. Fournal of Thoracic and Cardiovascular Surgery, 58, 773-782.

Requests for reprints to Dr Ib Kruse, Department of Anaesthesiology, Central Hospital, S-541 01 Skövde, Sweden. 